\title{
Glucosinolates on the leaf surface perceived by insect herbivores: review of ambiguous results and new investigations
}

\author{
Erich Städler • Kerstin Reifenrath
}

Received: 16 March 2008/Accepted: 13 August 2008/Published online: 18 September 2008

(C) Springer Science+Business Media B.V. 2008

\begin{abstract}
Herbivorous insects identify their host plants either by structural features, chemical cues, or a combination. Some insects probe the host leaf prior feeding or oviposition, other species use olfactorial cues or compounds somewhere on the surface. Insects attacking Brassicaceae are no exception, some are attracted and stimulated by volatile isothiocyanates (ITC), many others depend fully on the non-volatile glucosinolates (GS) for host-plant recognition and acceptance. Since most insects have no access to the leaf interior investigators concluded that GS must be present on the leaf surface and ITC in the headspace. However, peelings of mechanically removed surface waxes were devoid of measurable amounts of GS, whereas solvent surface extractions revealed a correlation between stomatal conditions and GS concentrations. Both observations lead to the conclusion that the presence of GS on the top leaf
\end{abstract}

E. Städler $(\bowtie)$

Department of Environmental Sciences, Conservation

Biology, University of Basel, St. Johanns-Vorstadt 10,

CH-4056 Basel, Switzerland

e-mail: Erich.Staedler@unibas.ch

\section{E. Städler}

Balmisacher 8, CH-8824 Schönenberg, Switzerland

K. Reifenrath

Ecological Field Station Fabrikschleichach, University of Würzburg, Glashüttenstr. 5, D-96181 Rauhenebrach,

Germany surface is rather unlikely. In the experimental part we show that a chloroform/methanol/water (2:1:1 vol/ $\mathrm{vol} / \mathrm{vol}$ ) solvent leaf extract contains GS and, in addition, thia-triaza-fluorenes (TTF), other oviposition stimulants of the cabbage root fly, Delia radicum. Electrophysiological investigations showed that both, GS and TTF stimulated specific receptor neurones of the fly. We suggest that these compounds probably originated from deeper leaf layers and that herbivorous insects may penetrate the wax layer and perceive the stimulating compounds in deeper layers or through the stomata.

Keywords Chemoreceptor neurones ·

Herbivore insects - Gustation - Leaf surface wax ·

Olfaction

\section{Abbreviations \\ GS Glucosinolates \\ ITC Isothiocyanates \\ TTF Thia-triaza-fluorene}

\section{Review of the evidences for glucosinolates (GS) on the leaf wax surface}

General observations

The first published report with a clear indication that secondary compounds present in Brassicaceae, most likely glucosinolates (GS), play an important role in 
host-plant selection of different herbivores was by de Candolle (1804), translated into German and interpreted by Perleb (1818). It was another 100 years before Verschaffelt (1910) presented the first experimental evidence for the stimulatory effect of GS on caterpillars of Pieris brassicae L. (Lepidoptera, Pieridae). Since then many more herbivorous insects and their parasites have been found to respond to GS or isothiocyanates (ITC) with oviposition, feeding or parasitation of herbivores of Brassicaceae (reviewed in Städler 2002; Schoonhoven et al. 2005).

The authors of many earlier studies assumed that the secondary plant compounds mediating host-plant selection have to occur on the leaf surface. Bernays et al. (1975) were first to point out the general importance of the undamaged leaf surface that harboured cues for herbivorous insects into accepting or rejecting host plants. In the meantime we have become acquainted with many more examples of herbivores, parasites and predators responding to plant surface compounds that vary widely in polarity and size (Eigenbrode and Espelie 1995; Städler 2002; Müller 2006).

Investigations of the distribution of myrosinases, enzymes responsible for GS degradation, have shown that these enzymes occur in the mesophyll in separate cells (myrosin cells) or cell compartments, close to or even in the epidermal cells (references in Thangstad et al. 2001; Andréasson and Jørgensen 2003) and apart from the GS. Further, Thangstad et al. (2004) used myrosinase gene promoters fused to the beta-glucuronidase (GUS) reporter gene and introduced into Brassica napus L. and Arabidopsis thaliana (L.) Heinh. (Brassicaceae) to determine the cell types expressing the myrosinase genes and the GUS expression regulated by these promoters. The authors showed that the promoter directs expression to guard cells (of stomata) and phloem myrosin cell idioblasts. These findings indicate that myrosin cells must be present in the epidermis, and suggests the presence of GS in the close vicinity, a conclusion drawn also by Agerbirk et al. (2008; review in this issue).

But as reviews by Müller and Riederer (2005) and Müller (2006, 2008) pointed out, verifying the existence of behaviourally active plant compounds on or in the leaf surface is much more difficult than assumed by many investigators (Städler and Roessingh 1991; Renwick et al. 1992; van Loon et al.
1992; Städler 2002). The GS that are in the primary focus of this review certainly belong to this category of compounds. Contradictory evidence is put forward for both the existence and the absence of GS or their breakdown products, the ITC and others, on plant surfaces. An open question remaining was whether the surface extracts used so far that were shown to stimulate the host-plant selection behaviour of different insects and their chemoreceptor neurones, contain not only compounds washed from intact plant surfaces, but in addition compounds originating from the mesophyll. In this review we combine data from more selective plant surface extractions (Reifenrath et al. 2005) with new data on the ability of such extracts to stimulate different sensory neurones of the tarsal sensilla of Delia radicum L. (Diptera, Anthomyiidae), and draw further conclusions about origin and availability of the active components.

Probable routes of plant secondary compounds to the leaf surface

Figure 1 adapted from Jeffree (1986) shows a schematic cross section of the plant cuticle. Important to note is that the living epidermal cells are covered by several layers of non-polar materials that present a complex barrier to the outside world (Jeffree 1986, 1996). The epicuticular wax layer, usually covered by wax crystals, represents the outermost leaf surface. The thickness of this leaf wax coat is in the order of $10 \mu \mathrm{m}$ for Brassica napus L. var. Martina (Reifenrath, unpublished). Holloway et al. (1977) investigated epicuticular wax in three lines of Brassica napus that varied in appearance (glossy versus normal leaves). The difference in appearance correlated with variable chemical compositions a distinct chemical make-up of the crystallite structures. Overall the main components were alkanes (C29 82\% and C31 $16 \%$ ) followed by ketones, secondary alcohols. Koch et al. (2006) studying the leaf surface wax of Brassica oleracea L. identified the same compounds.

The leaf surface has several very important functions for the plant and its different organs (Müller and Riederer 2005): firstly, it is a transpiration barrier. Secondly, it is the first line of defence against various organisms, since the wax layer may discourage herbivorous insects from feeding 
Fig. 1 Schematic cross section through the leaf cuticle, adapted from Jeffree (1986). According to Koch et al. (2006) wax tubules are about $7-10 \mu \mathrm{m}$ in length when $B$. oleracea leaves are grown at $40-70 \%$ $\mathrm{RH}$

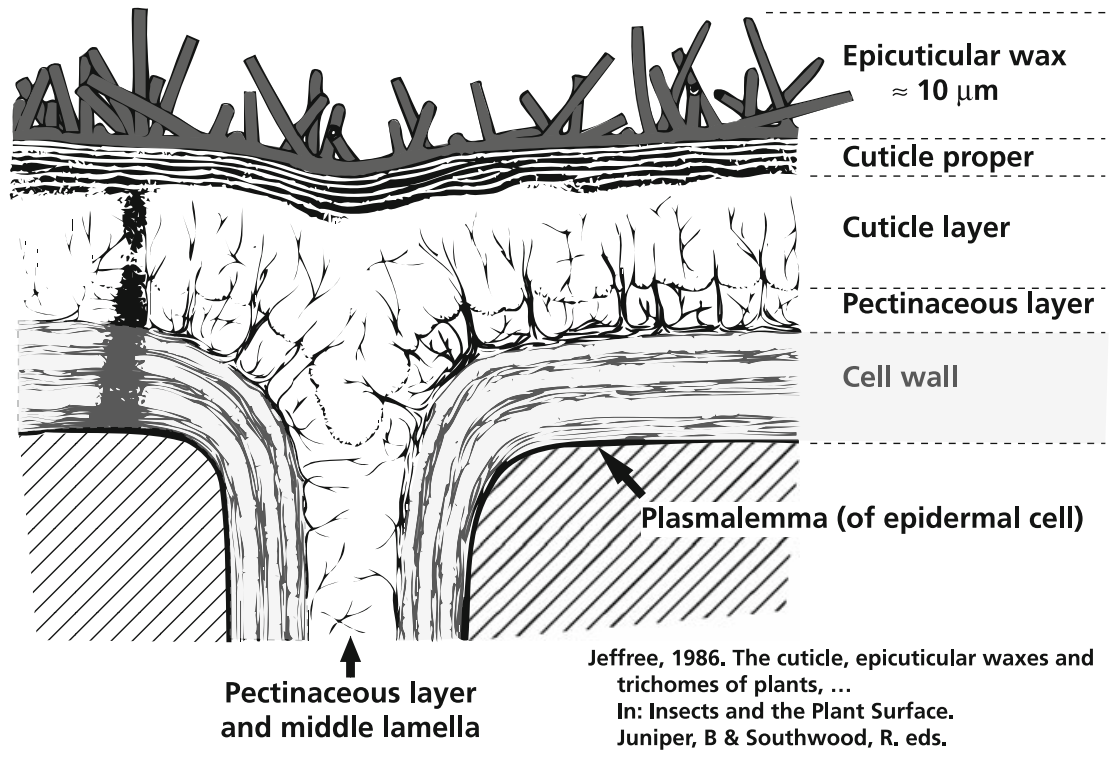

(Reifenrath et al. 2005). Thirdly, the wax crystals mediate slipperiness for herbivores (Eigenbrode and Jetter 2002) and reduce the wetting ability that is important for microbial pathogens (Knoll and Schreiber 2000). Fourthly, the cuticle is a shield against harmful UV radiation (Long et al. 2003).

The permeability of the cuticle for apolar and polar substances has been studied in isolated cuticle membranes of Hedera helix L. (Araliaceae) by Popp et al. (2005). The authors found that hydrophilic and lipophilic compounds differ in their ability to penetrate the membranes. Two different pathways were detected; a lipophilic pathway allows non-polar compounds to pass through the cuticle, whereas polar compounds can be transported via a hydrophilic pathway. However, based on observations of a hindered diffusion in narrow pores of molecular dimensions, the hydrophilic pathway was characterised by pronounced size selectivity, resulting in a decline in transport probability with increasing size and polarity of the molecule. For isolated cuticles of leaves of $H$. helix L. without stomata a threshold value was determined: exclusively carbohydrates with a molar volume smaller than $110 \mathrm{~cm}^{3} \mathrm{~mol}^{-1}$ were transported via the hydrophilic pathway (Popp et al. 2005). A diffusion of the GS sinalbin (4-hydroxybenzyl GS) with a much larger volume of about $270 \mathrm{~cm}^{3} \mathrm{~mol}^{-1}$ did not occur in Hedera cuticles (Müller and Riederer 2005). Assuming somewhat higher permeability for Brassicaceae, GS might still not pass the cuticle, but due to a smaller molar volume, the likelihood of TTF $\left(157 \mathrm{~cm}^{3} \mathrm{~mol}^{-1}\right)$ passing through the cuticle might be higher.

The cuticle layers are practically impermeable for water vapour and larger polar compounds (Müller and Riederer 2005). The only larger openings are the leaf stomata, which allow the gas exchange necessary for photosynthesis, respiration and transpiration. Probably most volatiles measured in the headspace of plants, including the Brassicaceae, were released through the stomata (Müller 2006), as already suggested by Dethier (1975). However it should be noted that the pathway of volatiles emanating from undamaged plants needs to be investigated in much more detail. The stomata of leaves exposed to light are known to be open whereas in the dark they are closed. Since the leaf surface extracts of light exposed plants contained significantly higher concentrations of non-volatile GS than the surface extracts of plants kept in darkness Reifenrath et al. (2005) suggested that the GS might have been washed out from the mesophyll through open stomata. Moreover, solvent extracts of upper and lower surfaces of plants showed marked differences in GS concentrations that were clearly correlated with the stomatal density of the respective leaf surface. Thus, the GS amounts reported to be in these solvent leaf surface extracts of light-exposed plants may not represent the actual concentration on the surface. 
Further, Reifenrath et al. (2005) confirmed this conclusion by removing the outermost epicuticular wax layer mechanically with gum arabic (avoiding the use of solvents) and finding no GS in this layer.

Insect reactions to wax and GS interactions

If GS are applied on non-host leaf surfaces such as Phaseolus vulgaris L. (Fabaceae) (Renwick et al. 1992) or on paraffin wax, they are available for detection by herbivores along with the ubiquitous plant waxes, predominantly alkanes in Brassicaceae. This was demonstrated in the case of the cabbage root fly by Roessingh and Städler (1990) who developed an artificial surrogate leaf to test plant extracts that stimulate oviposition. The systematic study of the physical characteristics of acceptable artificial leaves revealed that a surface covered in paraffin wax was an essential feature that acted synergistically with the applied plant extracts or GS sprayed on it. Other smooth coatings of the paper leaves did not stimulate the flies. The authors tried to find out if the chemical or physical properties of the paraffin were responsible for the synergistic effect by spraying the surrogate leaves with paraffin dissolved in hexane or by dipping the leaves in molten paraffin. The preference shown for the dipped leaves clearly indicated that the physical aspect of wax was of importance.

Spencer (1996) reported essentially similar result for the moth Plutella xylostella (L.) (Lepidoptera, Plutellidae). Sinigrin (2-propenyl GS) alone at $10^{-5}-10^{-2} \mathrm{M}$ acted as oviposition stimulant; but the addition of alkane made all sinigrin concentrations much more stimulatory than controls at $10^{-6}-10^{-2} \mathrm{M}$. Waxes alone did not stimulate oviposition. In choice tests, insect movement between sinigrin/alkane treatment combinations was random. However, once encountered, visit duration was significantly longer on sites treated with a mixture of sinigrin with alkane than on sites treated with either stimulus alone. Spencer et al. (1999) confirmed the earlier results and found that this preference arises because the additional time females spend in contact with the alkane treatment increases the speed at which they experience the available stimuli. The authors suggested that the presence of alkane may alter the way sinigrin is perceived, probably with receptor neurones on the antenna.
Volatile and non-volatile leaf surface compounds affecting herbivorous insects

\section{Extraction of behaviourally active compounds}

ITC concentrations are very low in the headspace above undamaged plants (Finch 1978; Tollsten and Bergström 1988; Rohloff and Bones 2005). This makes it unlikely that herbivorous insects locate Brassicaceae host plants over large distances by olfaction. But the presence of volatiles concentrated in the boundary layer could explain the synergistic effects of volatiles with non-volatile compounds in the host plant. Such synergistic effects of volatile host-plant compounds have been observed in different insects (refs in Städler 2002). An example reported by de Jong and Städler (1999) is the effect of Brassica volatiles, probably including ITC, on the oviposition behaviour of Delia radicum in contact with the host plant. The authors found no difference in the number of landings of flies but more mature females descended from these leaves when odour was present. However, in another insect, the turnip sawfly, Athalia rosae L. (Hymenoptera, Tenthredinidae) both volatile and non-volatile host-plant compounds seem equally important. The larva sequester GS from their cruciferous host plants in the larval stage (Müller et al. 2001) that protect them from antagonists and therefore, the host-finding behaviour of the female sawflies was of special interest. Barker et al. (2006) found that allyl ITC attracted experienced females in a four-chambered olfactometer, whilst naive females showed no response. As in the cabbage root fly (Finch and Skinner 1982) mentioned above, allyl ITC also attracted mature females of $A$. rosae to baited yellow water traps in field trials, although immature females were repelled at high ITC concentrations. In laboratory behavioural bioassays the GS sinigrin and sinalbin applied on filter paper stimulated ovipositor probing in mature females. This indicated that both ITC and GS were primarily involved in locating and accepting the host. Based on the available investigations it can be concluded that the role of ITC in long distance host-finding by Brassicaceae specialists seems variable, whereas GS seem to have a stimulatory effect (in contact) in all species studied so far.

The classical leaf surface extraction method by dipping leaves into chloroform (Juniper and Jeffree 
1983) yielded almost no oviposition activity in D. radicum (Städler and Roessingh 1991). Only a subsequent $\mathrm{MeOH}$ dip did result in stimulatory extracts. In these extracts Roessingh et al. (1992) and Griffiths et al. (2001) were able to identify GS. They verified that individual GS stimulate oviposition and the tarsal receptor neurones of $D$. radicum. Van Loon et al. (1992) used a similar combination of two different solvents for the extraction of the surface of Brassica oleracea (dipping these leaves for $3 \mathrm{~s}$ in $\mathrm{CHCl}_{2}$ followed by a $3 \mathrm{~s}$ dip into $\mathrm{MeOH})$. The $\mathrm{MeOH}$ extract stimulated oviposition activity in Pieris brassicae females. The most stimulatory compound could be identified as glucobrassicin (indol-3-yl-methyl GS). When pure glucobrassicin was offered at a dose identical to that in the crude $\mathrm{MeOH}$ extract, butterflies did not discriminate between these two substrates in a dual choice test, showing that GS are most likely the predominant stimuli in host-plant recognition and no other active compounds are involved. De Vos et al. (2008) added a new aspect by pointing out that Pieris rapae L. were exposed not only to the intact GS but also to the breakdown products in these assays. The authors extracted fresh leaves harvested from Arabidopsis thaliana plants and dipped them into $100 \%$ methanol $(\mathrm{MeOH})$ for 5-20 s, while keeping the cut petiole out of the solution. As a check for potential leaf damage they recorded the absorption at 647 and $660 \mathrm{~nm}$ (chlorophyll $a$ and $b$, respectively). Since the extract did not significantly differ from blank controls there was no significant cell damage occurring. The authors suggested that the expression of both myrosinase and epithiospecifier protein near the leaf surface might explain the presence of GS breakdown products, which they detected in these extracts. Indole-3-carbinol rather than the intact GS increased oviposition, whereas indole-3-acetonitrile decreased oviposition in P. rapae. Obviously, the stability of GS applied on non-host or surrogate leaves cannot be taken for granted and should be verified. Presumably, electrophysiological recordings from receptor neurones ( $P$. napi L. and P. rapae) with GS solutions as used by Du et al. (1995) and Städler et al. (1995) are probably less prone to the reported breakdown (further details under "Insect receptor neurones for GS and ITC").
Oviposition behaviour released by intact

leaf surface

Terofal (1965) first observed the oviposition behaviour of Pieris brassicae, P. napi and P. rapae in detail. The author confirmed the results of earlier experiments which showed that perception of colour (bright green) from a distance was an important landing stimulus. Landing was followed by drumming with the front (prothorax) legs on the leaf surface. Host acceptance depended entirely on contact with the host plant. In the field butterflies sometimes contacted up to 12 non-host plants before the real host plant was found. Unsuitable plants and dried leaves of hosts were contacted for no longer than $1 \mathrm{~s}$. Drumming with the front legs was interpreted as behaviour performed to produce a wind current that would stir up the boundary air layer of the leaf with its accumulated odours. The author observed that small plots of crop plants (Brassicaceae) were as attractive as large plots of host plants and thus he surmised that host-plant odours play no or only a minor role. These observations were later confirmed for P. rapae by Root and Kareiva (1984). These authors found that females in the field searching host plants for oviposition tended to follow linear flight paths (different from flights in search of food) and that they typically passed over many suitable hosts without landing. Both results indicate again that host plant odours have no significant influence on host-plant selection by this butterfly over relative short distances.

In the lab Terofal (1965) found that n-butyl-phenyl ITC or host-plant juice odour source applied either on non-host plants or green cardboard did not trigger oviposition behaviour of the three Pieris species and no oviposition took place. In contrast three non-host plants treated with host-plant juice received many ovipositions and eggs. A mixture of GS (mostly sinalbin and glucotropaeolin) was also active, and Phacelia tanacetifolia Benth. (Boraginaceae) leaves dipped in pure $0.1-1.0 \%$ sinigrin solution stimulated oviposition. Amputation of the front (prothorax) legs did not reduce oviposition because the host plants were still chosen by all three Pieris species. In $P$. brassicae the second or third pairs of legs could also be ablated and were not essential as long as the butterflies held on to the leaf. Females without 
antenna and without drumming were able to select their host plants. Thus chemoreceptor neurones of the sensilla (mostly olfactory) on the antenna were not required for host acceptance by the three Pieris species.

Ma and Schoonhoven (1973) developed an effective method to demonstrate the importance of stimulants close to the leaf surface. The authors immersed the petioles of non-host leaves (Vicia faba L., Fabaceae) in sinigrin or sinalbin solutions. Female butterflies of $P$. brassicae responded to these leaves and laid eggs on the non-host. The authors concluded that transport of GS onto or near the leaf surface must be relatively fast $(\approx 24 \mathrm{~h}$ ) since the female started to lay eggs after that period.

As the earlier mentioned butterflies Pieris rapae and P. brassicae (Renwick et al. 1992; van Loon et al. 1992) the cabbage root fly is also stimulated by GS to oviposit in the soil around the host plant or a surrogate leaf. But important in this insect the GS were found to be far less active stimulants than the TTF isolated and identified by Roessingh et al. (1997), Hurter et al. (1999) and de Jong et al. (2000) from leaf surface extracts (for details see below). Like some larval insects presented in the following section the cabbage root fly is an example of a crucifer insect responding not only to GS but also to other host-plant (Brassicaceae) compounds.

\section{Caterpillar and beetle larvae host-plant selection}

Terofal (1965) also observed the host-selection behaviour of larvae of Pieris brassicae, P. napi and, $P$. rapae in the field and the lab. He found that caterpillars perform a zig-zag movement over a host leaf covered with a net. But this happened only if the net was less than $5 \mathrm{~mm}$ away from the leaf surface. He inferred that caterpillars orient visually to a food plant in a range of $50 \mathrm{~cm}$, and that the first bite response is triggered by odours. After biting into the leaf feeding continues only if GS are present, a finding that confirmed earlier observations by Dethier (1954).

Since larvae bite into the leaf surface it is more difficult to judge if they react to compounds on the leaf surface. Biting reactions in response to GS stimulants on different surfaces can be an indication and Thorsteinson (1953) and Ma (1972), experimenting with the caterpillars of Plutella xylostella and Pieris brassicae, observed biting of non-host leaves treated with glucocheirolin (3-methylsulfonylpropyl GS), sinalbin and sinigrin. Thresholds of the GS stimulants for Plutella were $>2 \mathrm{ppm}$ ( $\approx 5 \mu \mathrm{M}$ sinigrin), and $20 \mathrm{ppm}$ for sinalbin (Thorsteinson 1953). Pieris brassicae caterpillars prolonged first biting in response to $4 \mathrm{mM}$ sinigrin (Ma 1972). The mustard oils (ITC) were less active than the parent glucosinolates and Thorsteinson (1953) concluded that the olfactory stimuli might initiate feeding "more promptly".

Phaedon cochleariae (F.) (Coleoptera, Chrysomelidae) larvae were induced to bite also by ITC and, as in the Pieris caterpillars, feeding continued only in the presence of mustard oil glucosides (Tanton 1977). Another insect that reacts not only to GS but also to flavonoids is the diamond back moth (Plutella xylostella). Van Loon et al. (2002) used pea (Pisum sativum L., Fabaceae) as a neutral non-host for a dual-choice leaf disc assay and tested GS and flavonoids as feeding stimulants for the caterpillars. Increasing concentrations of sinigrin resulted in significant preferences for sinigrin-treated over untreated non-host leaf discs, with a threshold between 1 and $3 \mu \mathrm{M}$. Millimolar concentrations of four of the five flavonol triglucosides likewise elicited a significant preference for flavonoid-treated over untreated non-host leaf discs. A mixture of four flavonoids and sinigrin was significantly preferred over sinigrin-treated leaf discs alone. Thus, one can conclude that there is considerable difference in the stimulatory effects of GS with variable side chains. In addition, for some insects the effect is further dependent on the combination with other chemical plant compounds (ITC, TTF, flavonoids).

\section{Beetle host-plant selection}

Reifenrath et al. (2005) studied the feeding behaviour of adults of Phaedon cochleariae (F.) (Coleoptera, Chrysomelidae) and found that leaf discs of the host plants Brassica napus L. and Nasturtium officinale R.Br. (Brassicaceae), whose epicuticular waxes had been removed with gum arabic, were preferred over intact surfaces. Sinigrin and/or non-polar surface wax extracts of B. napus or $N$. officinale leaves applied on Pisum sativum L. leaf 
discs did not provoke feeding, but feeding did occur when total-methanolic leaf extracts of B. napus or $N$. officinale were applied on this non-host. The authors concluded that GS might only act as feeding stimulants for $P$. cochleariae in concert with compounds other than surface waxes. Bioassay-guided fractionations of Sinapis alba L. (Brassicaceae) leaf extracts showed that the combination of one fraction containing GS, among these sinalbin, and one flavonoid-containing fraction elicited feeding behaviour in this beetle (Reifenrath and Müller 2008). Nielsen (1978) had observed beetles of the same species feeding even in response to pure isolated GS, but the GS concentrations provided here were much higher than those detected in host plant leaf material tested by Reifenrath and Müller (2008).

Nielsen et al. (2001) used transgenic Arabidopsis thaliana plants with a four-fold increased content in total GS levels to test the feeding responses of flea beetles (Phyllotreta nemorum L. and P. cruciferae Goeze Coleoptera, Chrysomelidae). Although these changes in GS levels were rather dramatic, the acceptability of A. thaliana for the two flea beetle species was largely independent of the concentration. The authors concluded that the effect of GS on adapted insects depends on the chemical or physical environment in which the GS are found.

\section{Insect receptor neurones for GS and ITC}

The first GS receptor neurone sensitive to GS was discovered by Schoonhoven (1967) in the maxillary sensilla styloconica of Pieris brassicae caterpillars. Since that time many more insects and different organisms and organs have been studied. Apparently in the insects that attack Brassicaceae that were studied all had either GS or ITC receptor neurones or both (Table 1). Ma and Schoonhoven (1973) investigated the distribution of the tarsal sensilla of adult $P$. brassicae on the three pairs of legs of this butterfly and found that the B-type sensilla contained at least one receptor neurone sensitive to the GS sinigrin, sinalbin and tropaeolin (benzyl GS). These sensilla were most frequent $(n=95)$ on the prothorax legs and on the fifth tarsomer of the tarsus of females, whereas the corresponding legs of males had in general fewer B, but the same numbers of A sensilla (apparently not involved in the perception of hostplant compounds).
Several GS neurones especially those of the tarsal sensilla, for example of Delia radicum, have been shown not only to be selective (Roessingh et al. 1997) but also to be very sensitive, with thresholds for the most active GS of $10^{-8}-10^{-9} \mathrm{M}$ (Roessingh et al. 1992) and thus are perfectly adapted to GS occurring at low concentrations. In different Pieris species Du et al. (1995) and Städler et al. (1995) found evidence that these species have GS receptor neurones differing in their response profile to individual GS. This would allow these insects to discriminate not only between different concentrations (quantities) of GS but also between different GS structures (qualities). The various GS were similarly ranked in behavioural and electrophysiological tests of both D. radicum (Roessingh et al. 1992) and P. rapae (Städler et al. 1995).

So far the olfactory receptor neurones have mainly been studied using electroantennograms (EAG) that give a measure of the combined total of receptor potentials of many neurones of the antenna. Barker et al. (2006) recorded EAGs from the antenna of the sawfly Athalia rosae that revealed that four volatile ITC (allyl (2-propenyl) ITC, benzyl ITC, butyl ITC and iberverin (3-methylthiopropyl ITC)) were active at all doses presented including the lowest $(0.1 \mu \mathrm{g})$. Important is that allyl ITC also influenced the behaviour of this sawfly as noted above. Blight et al. (1995) found that ITC, goitrin (5-vinyl-2-thiooxazolidone), and probably indole and benzyl cyanide, all catabolites of glucosinolates, were also perceived by the chemosensory neurones of the antenna of $\mathrm{Ceu}$ torhynchus assimilis Paykull (Coleoptera, Curculionidae). The authors used not only EAGs but in addition the single sensillum (neurone) recording technique in combination with gas-liquid chromatography (GLC). Recently, Renwick et al. (2006) showed that EAGs obtained with ITC corresponded well with the observed stimulatory (oviposition) effect of these compounds in Plutella xylostella in which the responses of the moth antennae were most pronounced with those ITC that were also most active in the oviposition assays. The two prominent volatile components were isolated from active host-plant extracts and identified by mass spectrometry as the ITC iberin (3-methylsulfinylpropyl ITC) and sulforaphane (4-methylsulfinyl-3butenyl ITC). Further examples of olfactory receptors for ITCs are given in Table 1. 
Table 1 List of insects and receptor organs containing GS/ITC receptor neurones

\begin{tabular}{|c|c|c|c|c|}
\hline Species & $\begin{array}{l}\text { Brassicaceae } \\
\text { host/non-host }\end{array}$ & $\begin{array}{l}\text { Sensory } \\
\text { organ }\end{array}$ & Compounds/concentrations & References \\
\hline \multicolumn{5}{|l|}{$\mathrm{COL}$} \\
\hline $\begin{array}{l}\text { Ceutorhynchus assimilis } \\
\text { adult }\end{array}$ & Host & Antenna & ITC: allyl isothiocyanate, goitrin & $\begin{array}{l}\text { Evans and Allen-Williams } \\
\text { (1992); Blight et al. (1995) }\end{array}$ \\
\hline Psylliodes chrysocephala & Host & Antenna & GS: sinigrin, sinalbin, glucotropaeolin & Isidoro et al. (1998) \\
\hline Entomoscelis americana & Host & Maxilla & GS: sinalbin & Sutcliffe and Mitchell (1982) \\
\hline \multicolumn{4}{|l|}{ DIPT } & Messchendorp et al. (1998) \\
\hline Delia floralis adult & Host & Tarsi & $\begin{array}{l}\text { GS: Glucobrassicin, neoglucobrassicin } \\
\text { sinigrin, gluconapin, } \\
\text { glucobrassicanapin, progoitrin, } \\
\text { glucoerucin, glucoiberin, } \\
\text { glucotropaeolin, sinalbin, } \\
\text { gluconasturtiin }\end{array}$ & $\begin{array}{l}\text { Alborn et al. (1985); Blaney } \\
\text { and Simmonds (1994); } \\
\text { Simmonds et al. (1994); } \\
\text { Baur et al. (1996); Hopkins } \\
\text { et al. (1997); Gouinguené } \\
\text { and Städler (2006) }\end{array}$ \\
\hline \multirow[t]{2}{*}{ Delia radicum adult } & Host & Tarsi & $\begin{array}{l}\text { GS: Glucobrassicin, sinigrin, } \\
\text { gluconapin, glucobrassicanapin, } \\
\text { progoitrin, glucoerucin, glucoiberin, } \\
\text { glucotropaeolin, sinalbin, } \\
\text { gluconasturtiin }\end{array}$ & $\begin{array}{l}\text { Roessingh et al. (1992); Städler } \\
\text { et al. (2002); Gouinguené } \\
\text { and Städler (2006) }\end{array}$ \\
\hline & & Antenna & ITC: allyl isothiocyanate & Wallbank and Wheatley (1976) \\
\hline $\begin{array}{l}\text { Delia antiqua, } D . \text { platura, } \\
\quad \text { Psila rosae adult }\end{array}$ & Non & Tarsi & $\begin{array}{l}\text { GS negative: glucobrassicin, sinalbin, } \\
\text { sinigrin }\end{array}$ & Gouinguené and Städler (2005) \\
\hline \multicolumn{5}{|l|}{$\mathrm{HOM}$} \\
\hline $\begin{array}{l}\text { Aphis fabae, Brevicoryne } \\
\text { brassicae, Lipaphis erysimi }\end{array}$ & $\begin{array}{l}\text { Polyphagous } \\
\text { Host }\end{array}$ & Antenna & $\begin{array}{l}\text { ITC: 3-butenyl-, 4-pentenyl } \\
\text { isothiocyanate }\end{array}$ & Nottingham et al. (1991) \\
\hline \multicolumn{5}{|l|}{ HYM } \\
\hline Athalia rosae adult & Host & Antenna & $\begin{array}{l}\text { ITC: isothiocyanates (allyl } \\
\text { (2-propenyl) isothiocyanate, benzyl } \\
\text { isothiocyanate, butyl } \\
\text { isothiocyanate, iberverin } \\
\text { (3-methylthiopropyl } \\
\text { isothiocyanate)) }\end{array}$ & Barker et al. (2006) \\
\hline \multicolumn{5}{|l|}{ LEP } \\
\hline Pieris brassicae adult & Host & Tarsi & GS: sinigrin, sinalbin, glucotropaeolin & Ma and Schoonhoven (1973) \\
\hline Pieris brassicae caterpillar & Host & Maxilla & GS: sinigrin, sinalbin, glucotropaeolin & $\begin{array}{l}\text { Schoonhoven (1967); } \\
\text { Ma (1972) }\end{array}$ \\
\hline $\begin{array}{l}\text { Pieris rapae, } P . \text { oleracea, } \\
\quad P . \text { napi adult }\end{array}$ & Host & Tarsi & GS: glucobrassicin, gluconasturtiin & Du et al. (1995) \\
\hline Pieris rapae caterpillar & Host & Maxilla & GS: Gluconasturtiin & Miles et al. (2005) \\
\hline Plutella xylostella adult & Host & Antenna & $\begin{array}{l}\text { ITC: iberin (3-methylsulfinylpropyl } \\
\text { isothiocyanate) and sulforaphane } \\
\text { (4-methylsulfinyl-3-butenyl } \\
\text { isothiocyanate), methyl-, allyl-, } \\
\text { ethyl-, propyl-, butyl-, benzyl-, } \\
\text { phenyl-, phenylethyl- } \\
\text { isothiocyanates }\end{array}$ & Renwick et al. (2006) \\
\hline Plutella xylostella caterpillar & Host & Maxilla & $\begin{array}{l}\text { GS: sinigrin, glucocapparin, } \\
\text { glucobrassicin, glucoiberin, } \\
\text { gluconasturtiin }\end{array}$ & Van Loon et al. (2002) \\
\hline $\begin{array}{l}\text { Mamestra configurata } \\
\text { caterpillar }\end{array}$ & Polyphagous & Maxilla & GS: sinigrin & Shields and Mitchell (1995a, b) \\
\hline
\end{tabular}


Table 1 continued

\begin{tabular}{lllll}
\hline Species & $\begin{array}{l}\text { Brassicaceae } \\
\text { host/non-host }\end{array}$ & $\begin{array}{l}\text { Sensory } \\
\text { organ }\end{array}$ & Compounds/concentrations & References \\
\hline Mamestra brassica caterpillar & Polyphagous & Maxilla & $\begin{array}{l}\text { GS: sinigrin, glucocapparin, } \\
\text { glucotropaeolin }\end{array}$ & Wieczorek (1976) \\
Trichoplusia ni caterpillar & Polyphagous & Maxilla & GS: sinigrin & Mitchell et al. (1996) \\
Mamestra brassica adult & Polyphagous & Antenna & ITC: allyl isothiocyanate & Rojas (1999) \\
Heliothis virescens adult & Non & Antenna & GS: sinigrin & Jørgensen et al. (2006) \\
\hline
\end{tabular}

The listed examples are ordered by their insect order: Coleoptera (COL), Diptera (DIPT), Homoptera (HOM), Hymenoptera (HYM), Lepidoptera (LEP) beginning in each order with the species accepting Brassicaceae as hosts

Host: insect is attacking Brassicaceae as larva and/or adult

Polyphagous: generalist, not specialised herbivorous insect

Non: Brassicaceae mostly non hosts

\section{Perception of glucosinolates on leaf wax surface by Delia radicum: a new investigation}

As pointed out in the review it has been assumed by several investigators that mainly secondary plant compounds on the leaf surface lead to the acceptance of host plants. In the Brassicaceae the polar GS and non-polar ITC are mainly in focus because many herbivores attacking these plants respond to them alone or in combination (Table 1). But Müller and Riederer (2005) concluded that the presence of GS in epicuticular waxes is rather improbable and indeed Reifenrath et al. (2005) found no GS in the epicuticular waxes of Brassicaceae removed by gum arabic. This discrepancy needs to be solved eventually. Further, the earlier used surface extracts either contained no GS or in addition compounds from the leaf interior. The new extraction method used by Reifenrath et al. (2005), extracting either abaxial or adaxial surfaces of light- or dark-kept plants, has a much smaller risk to extract the leaf interior. This advance opened the opportunity to test for varying GS quantities in dependence of the different stomatal densities and closure conditions verify the earlier chemical GS analysis. Furthermore, an analysis of other polar compounds, the TTF (according to De Jong et al. (2000) mostly TTF-1 (1,2-dihydro-3thia-4,10,10b-triaza-cyclopenta[.a.]fluorene-lcarboxylic acid), TTF-2 (a conjugate of TTF-1 with the amino acid glycine) and TTF-3 (1,2-dihydro-6methoxy-3-thia-4,10,10b-triaza-cyclopenta[.a.]-fluorene-1-carboxylic acid), was included. In addition we could use the same extracts also to stimulate specific receptor neurones of $D$. radicum to confirm that this Brassicaceae specialist can perceive the known oviposition stimulants and potentially other compounds present in the extracts. We used Nasturtium officinale plants because of the earlier obtained experimental data and because some Nasturtium species are host plants of our test insect Delia radicum whose tarsal receptor sensilla and sensory neurones have earlier been studied in detail.

\section{Materials and methods}

Nasturtium officinale plants were grown and leaf extracts prepared at the University of Würzburg using the methodology described in Reifenrath et al. (2005). Briefly, the leaves were placed on a flexible rubber mat, a glass cylinder (13 $\mathrm{mm}$ diameter) was gently pressed onto the exposed surface, and the extracting solvent, a mixture of chloroform, methanol and aqua bidest $(2: 1: 1 \mathrm{vol} / \mathrm{vol} / \mathrm{vol})$ was applied to the adaxial and abaxial leaf surfaces, respectively, agitated for $20 \mathrm{~s}$ by pumping with a Pasteur pipette and then removed. This procedure was repeated twice. The three subsequent extracts were pooled separately from a total area of approximately $26 \mathrm{~cm}^{2}$ of individual leaves and reduced to dryness under a gentle air flow. In order to reveal the effects of stomatal conditions on the presence of secondary plant compounds in these extracts, half of the extracts were obtained from plants that were kept in darkness for 3-4 h prior to the extraction in order to ensure stomatal closure. The second half of the extracts was gained from plants kept under normal light conditions and with open stomata. GS were converted to desulphoglucosinolates using sulphatase and 
analysed by HPLC (for details see Reifenrath et al. 2005).

Thia-triaza-fluorene (TTF-1) in the extracts were analysed at Wädenswil with a API 4000 triplequadrupol mass-spectrometer (Applied Biosystems, Rotkreuz) with a Turbo Ion Spray-source linked to a binary HPLC pump (Agilent 1100 Series, Agilent Technologies Inc., Basel) and a LC PAL autosampler (CTC Analytics, Zwingen). The components were separated with a $2 \times 150 \mathrm{~mm}$ i.d. Synergi $4 \alpha$ FusionRP18 column (Phenomenex, Torrance, CA) and eluted with $0.1 \%$ formic acid in water (solvent $\mathrm{A}$ ) and $\mathrm{MeOH}$ (solvent $\mathrm{B}$ ). The elution gradient was from $95 \% \mathrm{~A}$ and $5 \% \mathrm{~B}$ to $40 \% \mathrm{~A}$ and $60 \% \mathrm{~B}$ in $15 \mathrm{~min}$, at a flow rate of $0.2 \mathrm{ml} / \mathrm{min}$. The ion source was in positive mode operating at $450^{\circ} \mathrm{C}$. For quantification and verification mass transitions of $272 \rightarrow 226$ and $272 \rightarrow 168$ were used at collision energies of 40 and $55 \mathrm{~V}$ respectively, which gave the highest signal intensity.

Delia radicum were continuously reared in the laboratory on the host plants cabbage (Brassica oleracea botrytis (L.)) and rutabaga (Brassica napus var. napobrassica (L.)) from the local market. The culture originated from maggots collected in 2003 from cauliflowers in central Switzerland. Tip recordings from the tarsal sensilla were made from the sensilla present on the prothorax legs (Städler and Roessingh 1991; Baur et al. 1996; De Jong and Städler 2001). For each fly, the different stimuli were tested on the ventro-lateral D-sensilla and the ventro- medial $\mathrm{C}_{5}$-sensillum on the fifth tarsomer (Fig. 3). The recordings were digitised and analysed with 'Spike Train Analysis' (STA, laboratory-built software to analyse electrophysiological recordings). The results were expressed as the number of spikes per second from $50 \mathrm{~ms}$ (avoiding the electric contact artefact) after contact with the sensillum to $1050 \mathrm{~ms}$.

Results and discussion

\section{Chemical analysis of the surface extracts}

The analysis of the GS extracts revealed that the most common GS was as expected gluconasturtiin (2-phenyl-ethyl GS) (Reifenrath et al. 2005). Extracting the leaf surfaces with a threefold short rinse with chloroform/methanol/water $(2: 1: 1 \mathrm{vol} / \mathrm{vol} / \mathrm{vol})$. The amounts of GS in the extracts depended on the light conditions under which plants had been kept in the period prior to extraction and on the leaf side, which was extracted. As GS amounts increased with the number of stomata and their openness, we assume that during extraction with organic solvents the GS were washed to the outside from the inner leaf tissue through open stomata.

As pointed out by Strauss et al. (2004) the optimal defence theory predicts that plant tissues most closely tied to plant fitness should be most defended at the constitutive level. In accordance, these authors found that GS vary greatly both within and among individuals. Shroff et al. (2008) used recently Matrix
Fig. 2 Amounts of thiatriaza-fluorene (TTF) extracted from the leaf surfaces of Nasturtium officinale using the method of Reifenrath et al. (2005)

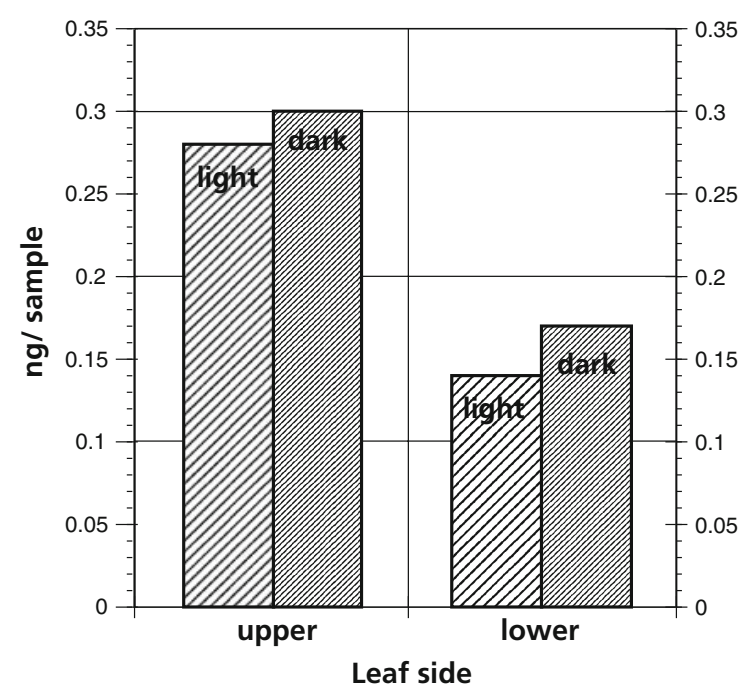

Thia-triaza-fluorene - 1

1,2-Dihydro-3-thia-4,10,10b-triaza -cyclopenta[.a.]fluorene-1-carboxylic acid 
Assisted Laser Desorption/Ionization-Time Of Flight (MALDI-TOF) mass spectra to show in detail the location of these plant defence compounds such as GS in Arabidopsis thaliana leaves. At the sensitivity threshold of their instrument the authors could not localise glucobrassicin or TTF on the intact leaf surfaces. These results thus confirm the data of Reifenrath et al. (2005) but also add interesting details. The GS were found to be preferentially allocated to tissues of the midvein and the periphery of the leaf. In contrast to the GS, the myrosinase was found to be uniformly distributed over the leaf. The feeding preference bioassays performed by Shroff et al. (2008) using Helicoverpa armigera (Lepidoptera, Noctuidae) larvae demonstrated that the outer edge of the leaf is more effectively defended than the inner tissue. This observation is related to earlier analysis of the oviposition behaviour of the cabbage root flies by Zohren (1968) and Städler and Schöni (1990). After landing on the host plants, the females were observed to follow the leaf edges and veins when stimulated to lay eggs in the soil near the plant stem. Thus the morphology of the leaf might only be a secondary cue for the flies leading them to the primary location of highest concentration of GS where they are stimulated.

Not only GS but also TTF were detected in the surface extracts prepared from $N$. officinale. In contrast to the GS the corresponding analysis of TTF in the same extracts gave a different distribution (Fig. 2). The TTF concentration in the extracts was not dependent on the light intensity the plants experienced prior to extraction, but the extracts of the lower side of the leaf contained slightly lower concentrations of the TTF compounds.

\section{Electrophysiological experiments}

The same extracts of $N$. officinale leaves exposed to light and darkness prior to extraction were also used for electrophysiological experiments with D. radicum. Tarsal sensilla and in addition $\mathrm{D}_{5}, \mathrm{D}_{2}$, and $\mathrm{D}_{1}$ were stimulated (Fig. 3). The representative recordings of a $\mathrm{D}_{3}$ sensillum (Fig. 4) and the corresponding analysis of all recordings from functionally identical $D_{3}$ and $D_{4}$ (Fig. 6a) show that both leaf surface extracts were highly stimulatory, affecting mainly one neurone, which must be the same as the one shown to be active in the recording with

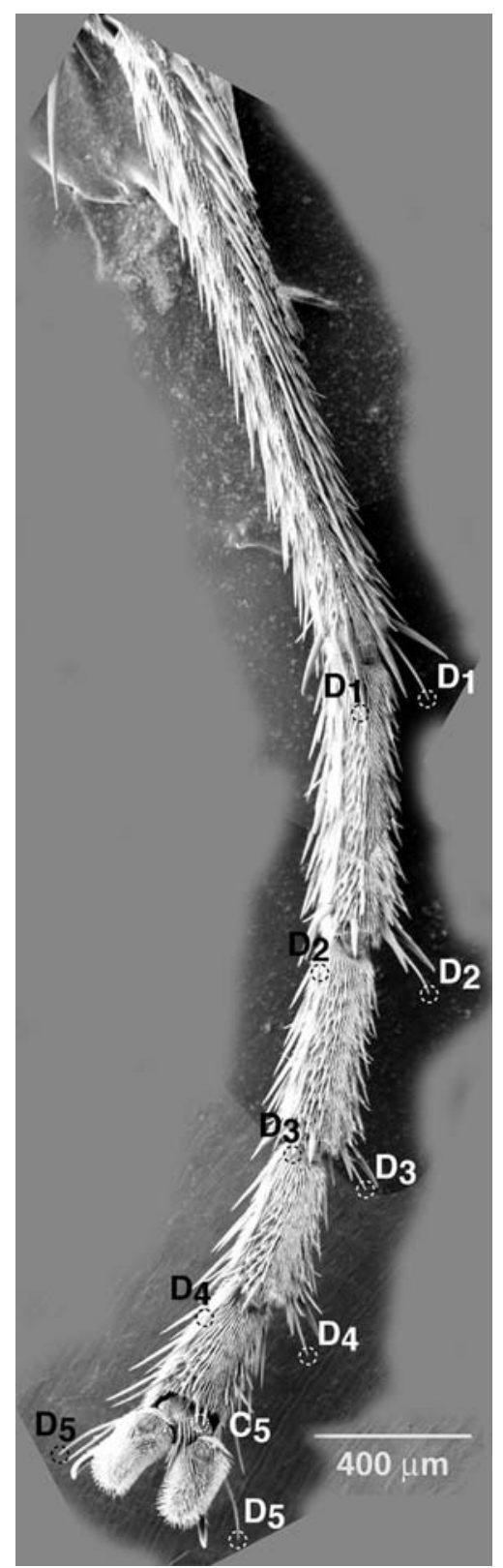

Fig. 3 Scanning electron microscopic view of the ventral side of a prothorax tarsus of a female Delia radicum. The D and C sensilla that are known to contain sensory neurones sensitive to GS and/or TTF are circled

glucobrassicin or sinalbin. Hundred millimolar sucrose stimulated as expected the sugar-sensitive neurone and this provided further evidence of the good quality of the preparations and sensilla investigated. The controls $(\mathrm{KCl} 30 \mathrm{mM}$ and $\mathrm{KCl} 30 \mathrm{mM}$ with $10 \% \mathrm{MeOH}$, note that surface extracts contained 
Fig. 4 Extra-cellular recordings from the tip porous of the same $\mathrm{D}_{3}$ sensillum of Delia radicum in response to four different stimuli. The first stimulus $10 \% \mathrm{MeOH}$ in $30 \mathrm{mM} \mathrm{KCl}$ is the control for the surface extracts (Reifenrath et al. 2005) that contain also $10 \% \mathrm{MeOH}$.

Glucobrassicin was the most active GS stimulant for the known GS-sensitive neurone in this and in the $\mathrm{D}_{4}$ sensillum
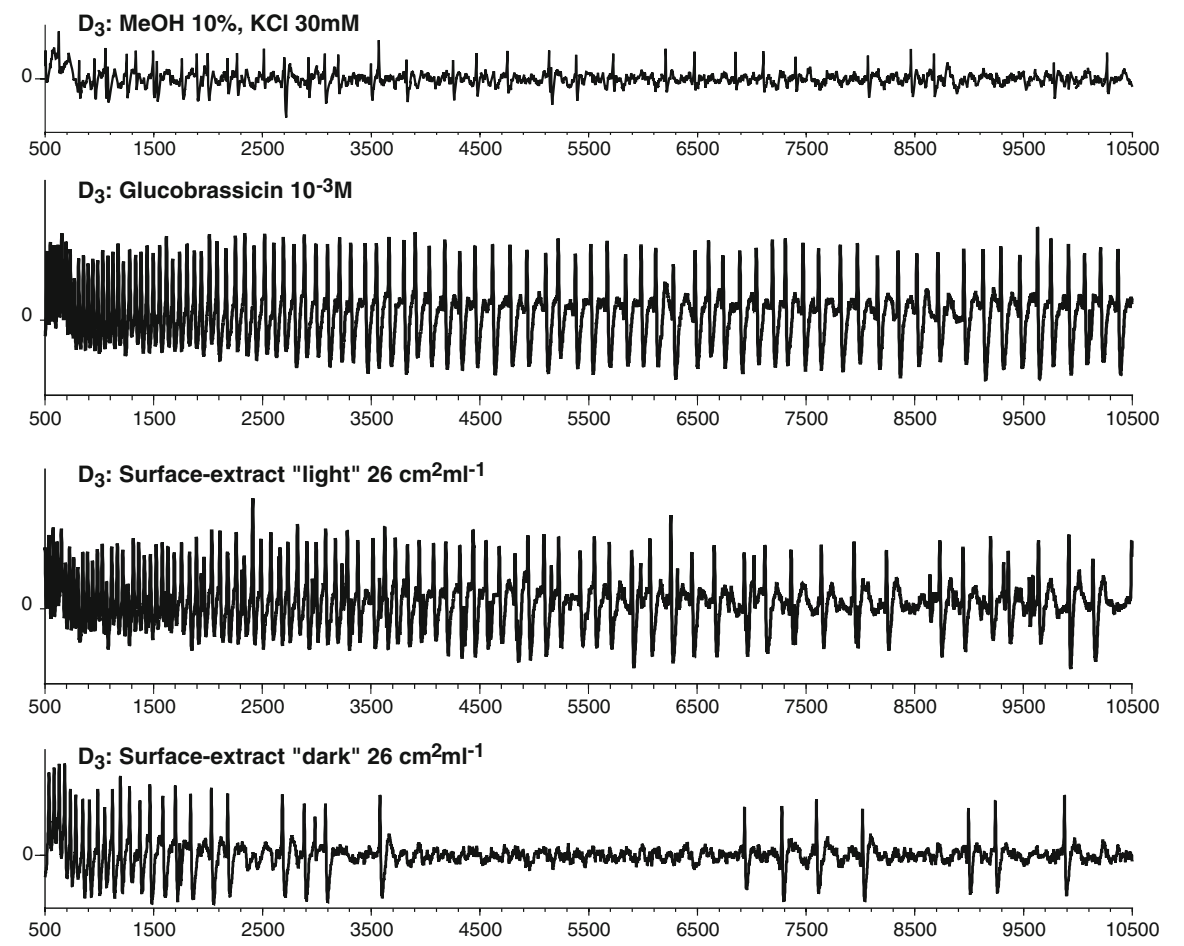

also $10 \% \mathrm{MeOH}$ in the electrolyte $\mathrm{KCl} 30 \mathrm{mM}$ ) were only slightly stimulatory for a neurone that was not identified. The extracts "light" from plants kept under light prior to extraction was usually more active than the extracts "dark" from plants kept in the dark, but the difference was not significant $(P=0.0836$; Wilcoxon test comparing the activity of the two stimuli in each tested sensillum). The recordings show clearly that the extract contained a relatively high concentration of GS (estimated below $10^{-3} \mathrm{M}$ but higher than $10^{-4} \mathrm{M}$ ).

The recordings from the $\mathrm{C}_{5}$ sensillum (Fig. 5) show that the GS neurone was far less sensitive to glucobrassicin than the TTF neurone that was strongly stimulated by the low concentration of $4 \times 10^{-8} \mathrm{M}$ thia-triaza-fluorene-1. Since the extract "light" and the extract "dark" had a high stimulatory effect certainly on one, or possibly two neurones it was evident that both extracts contained TTF as well as GS. This conclusion is further supported by the spike counts of tested neurones in Fig. 6b. Again the extract "light" was more active than the extract "dark" and the difference in the activity of the two extracts was significant in this comparison (Wilcoxon test $P=0.0438$ ). Finally the systematic analysis of the $D_{5}, D_{2}$ and $D_{1}$ sensilla shows that these sensilla contain also a neurone sensitive to sucrose (sugar neurone) but no neurones sensitive to GS or TTF. The two leaf surface extracts showed no $\left(D_{5}\right)$ or very little activity when compared with the controls. Interestingly the extract "light" was stimulatory for at least one neurone in $\mathrm{D}_{2}$ and $\mathrm{D}_{1}$ sensilla whereas the extract "dark" was not at all. Since the sucrose-sensitive neurone in the $\mathrm{D}_{2}$ and $\mathrm{D}_{1}$ sensilla was very active the extract "light" might contain some sugars. This is speculative because several other compounds could also be involved, although they are definitively neither GS nor TTF. Thus the recordings from the $\mathrm{D}_{5}, \mathrm{D}_{2}$ and $\mathrm{D}_{1}$ sensilla can be regarded as additional confirmation of the specific effects of the extracts on GS- and TTF-sensitive neurones (Fig. 7).

\section{Conclusions}

We confirmed that the cabbage root fly has very sensitive and specific receptor neurones in specific tarsal sensilla for GS and TTF, which were previously identified in our laboratory (Roessingh et al. 1997; de Jong et al. 2000). These receptor neurones perceive in accordance with the chemical analysis the extracts of upper and lower surfaces of plants 
Fig. 5 Extra-cellular recordings from the tip porous of the same $\mathrm{C}_{5}$ sensillum of females of Delia radicum in response to four different stimuli. Note that this sensillum contains according to the results of Roessingh et al. (1997) one neurone sensitive to GS and one to TTF. The spikes (recorded with the same amplification and electronic filtering) of the two neurones can be discriminated according to their size and shape. Thiatriaza-fluorene-1 (TTF) is the most active stimulus for one neurone.

Glucobrassicin (GS) stimulates a separate neurone weakly (in the same sensillum). The surface extracts used are the same as in Fig. 4a
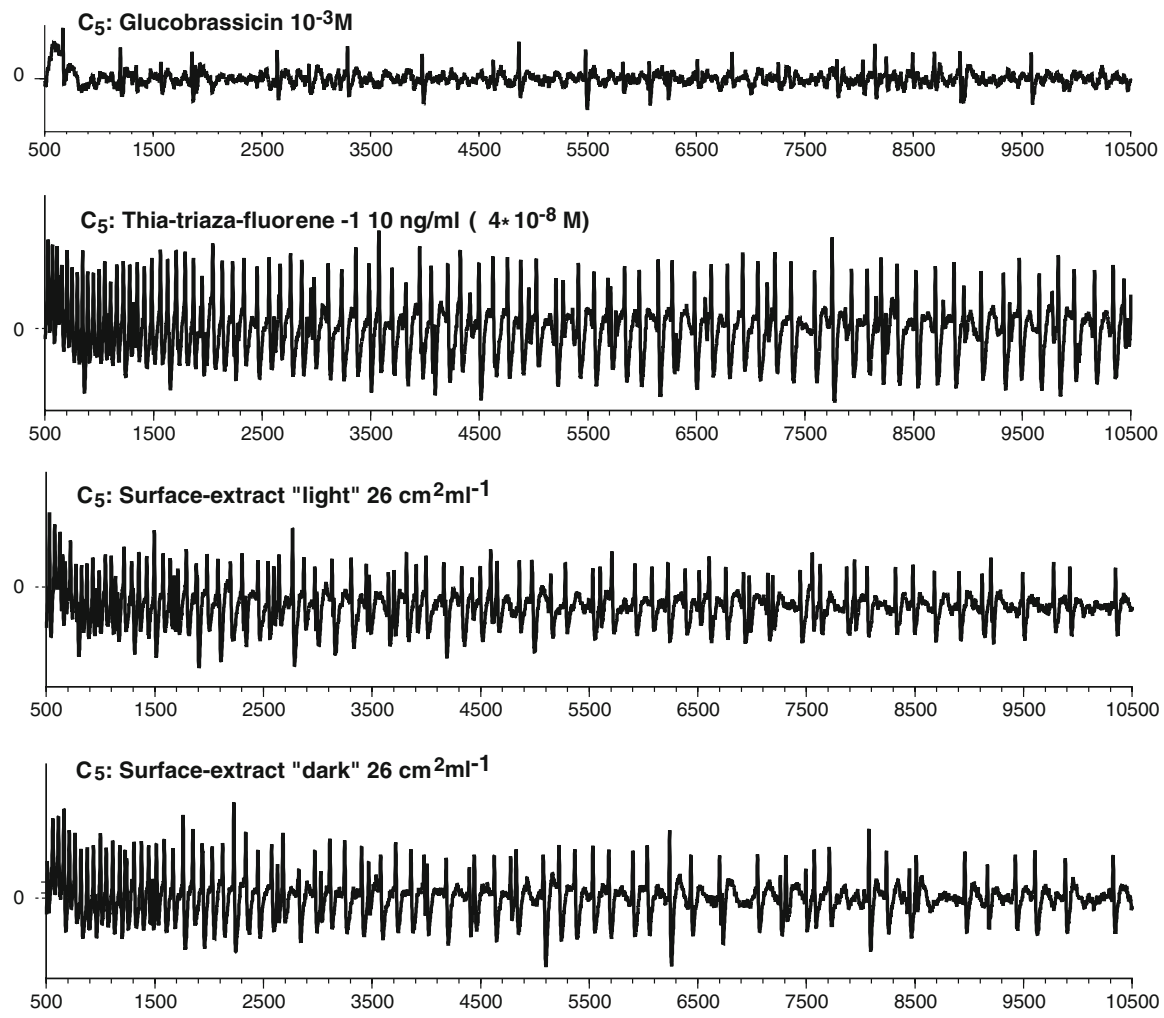

exposed prior to extraction to light and darkness, differently. In agreement with Reifenrath et al. (2005) we assume that GS in the extracts originate from inner leaf tissue and are washed through the open stomata. In contrast to GS the localisation and origin of TTF in Brassica leaf surfaces remains less clear. Due to a smaller molecular volume the transport of TTF through the intact cuticle is at least more likely than that of GS. This is supported by the observation that the TTF concentrations did not differ between extracts of leaves exposed to light and dark prior the experiments (Fig. 2).

There is overwhelming evidence that several herbivorous insects of Brassicaceae can perceive GS by contacting the surface of the leaves of Brassicaceae. But at present, we can only speculate how these insects can access the host-plant specific GS compounds. One possibility would be that the females either mechanically remove some of the waxes with their tarsal structures (spines) and thereby access the deeper layers below the wax. The depiction of the tarsal sensilla of D. radicum in Fig. 8 shows that the spines have a length of about $50 \mu \mathrm{m}$ and reach about $20 \mu \mathrm{m}$ further than the sensilla to the surface touched during walking. In contact with the leaf the spines could be envisaged to penetrated the epicuticular wax crystals (thickness $\geq 10 \mu \mathrm{m}$ in some Brassicaceae) and thus allow the sensilla with the sensitive neurones to touch deeper layers of the plant cuticle. Pieris butterflies also have spines on the ventral side of the tarsi (figure in Städler et al. 1995). In the case of Pieris rapae the spines are arranged so that they touch the leaf surface just in front of the groups of sensilla with GS receptor neurones, implying that these spines may have a function in the perception of plant compounds concealed under the leaf wax cover. Such a possibility has already been suggested for butterfly females of the Papilionidae. Bart and Williams (1993) applied dental wax on host plant leaves and allowed Papilio polyxenes Fabricius females to drum on these leaves and the applied wax. Scratches were not detectable in the leaf surface wax, but were revealed in the dental wax and showed that the spines these butterflies have on the ventral side of the tarsi can in principle damage the epicuticular wax of Pastinaca sativa (Apiaceae). Inoue (2006) followed up on this study and compared the ventral surfaces of the tarsi of many different Papilio species. 
Fig. 6 Results of all recordings and spike counts of (a) $\mathrm{D}_{3}$ and $\mathrm{D}_{4}$ sensilla, found to be functionally identical and therefore pooled and (b) $\mathrm{C}_{5}$ sensilla. Wilcoxon tests: for comparisons of the extracts "light" and "dark" with $41 \mathrm{D}_{3,4}$ receptor neurones $P=0.0836$ and with $22 \mathrm{C}_{5}$ receptor neurones $P=0.0438$
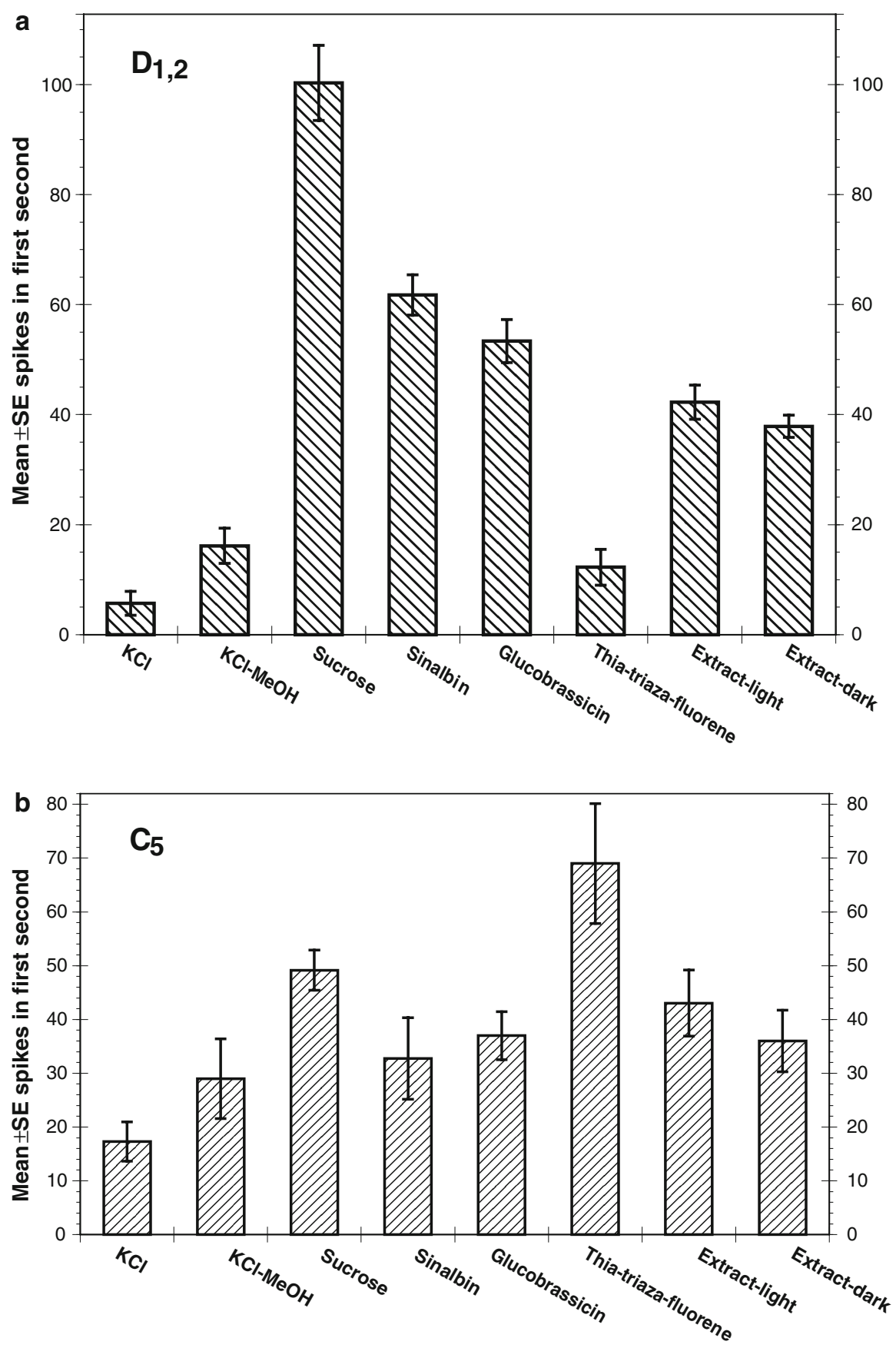

In accordance with Ma and Schoonhoven (1973), who investigated Pieris brassicae females, he found about three times more contact-chemoreceptor sensilla on the tarsi of female Papilionids than on males of the same species. Moreover, the female fore tarsi morphology corresponded to the physical features of their respective host-plant leaves. Namely, Papilio machaon L. (including $P$. polyxenes described in Roessingh et al. 1991), which oviposits on herbal Apiaceae with soft leaves, had more but shorter spines than the nine other Papilio species laying on the more robust leaves of Rutaceae plants. Furthermore, the chemoreceptor sensilla were more concentrated on the fifth tarsomer, the one with the 
Fig. 7 Results of all recordings and spike counts from $\mathrm{D}_{5}, \mathrm{D}_{2}$ and $\mathrm{D}_{1}$ sensilla where $D_{2}$ and $D_{1}$ appeared to be functionally identical and are therefore pooled. Wilcoxon tests for comparisons of the extracts light and dark with $16 \mathrm{D}_{5}$ receptor neurones $P=0.0021$ and $8 \mathrm{D}_{1}$ and $\mathrm{D}_{2}$ receptor neurones $P=0.0117$
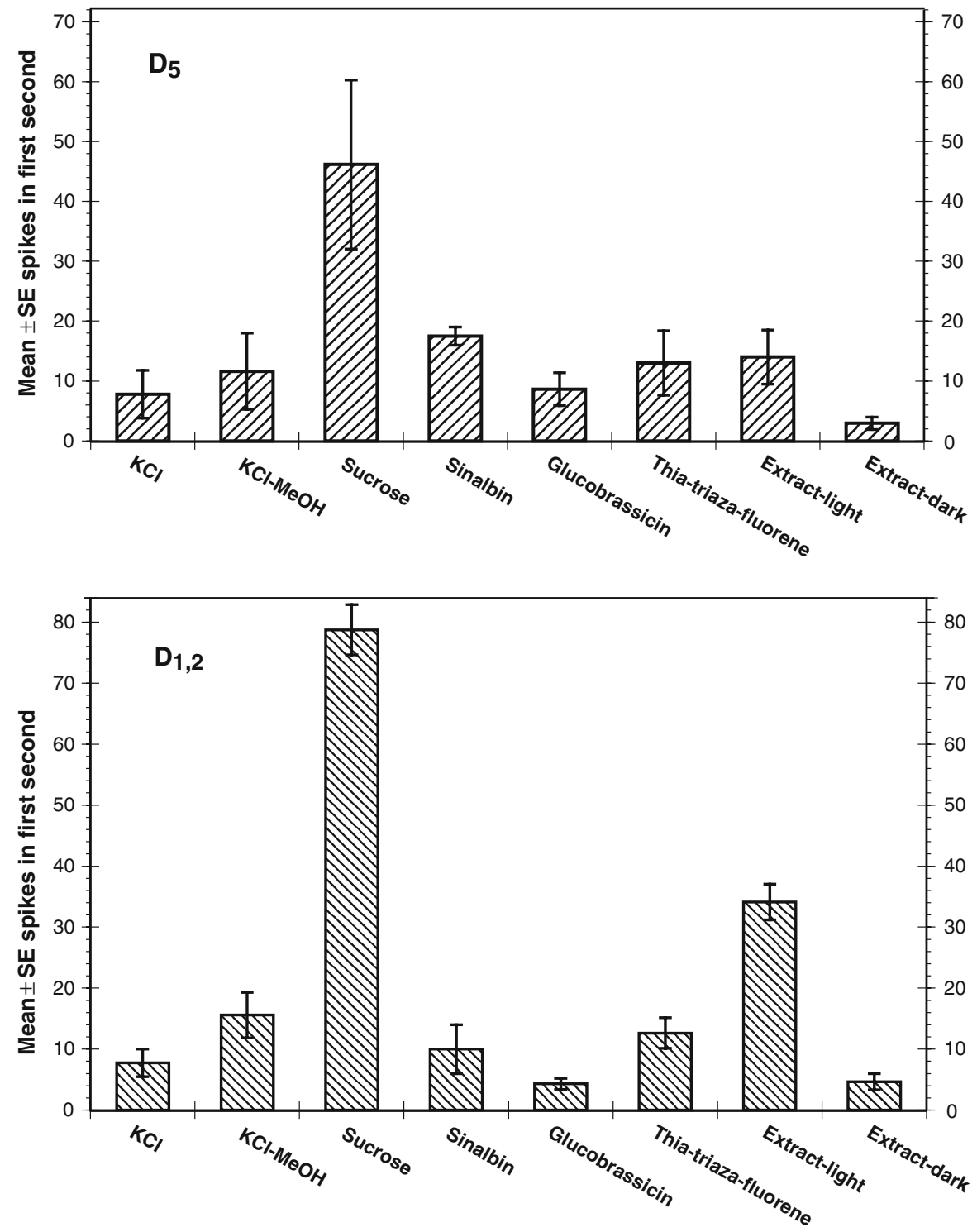

highest impact on the leaf surface. This finding can be regarded as an additional indication that the spines studied are indeed involved in the perception of plant compounds on the surface. The monarch butterfly Danaus plexippus L. (Lepidoptera, Danaidae) is yet an other example of an insect having special structures on the front legs used for drumming leaf surfaces. Baur et al. (1998) made recordings of receptor neurones of gustatory sensilla on the prothorax tarsi of females. The tips of these sensilla are pointing into the grooves of large spines that apparently allow the collection of compounds during the drumming of the leaf surfaces by the butterfly.
A second hypothesis is that the individual sensilla might contain a protein with properties, called by the authors "Takeout-like protein", as has been found in the taste organs of the blowfly, Phormia regina Meigen (Diptera, Calliphoridae) by Fujikawa et al. (2006). Such ligand-binding proteins may penetrate the wax layer and "mobilise" the polar compounds in the deeper layers of the leaf surface.

Thirdly the question can be raised if the tarsal sensilla of the Delia flies and Pieris butterflies may reach into the stomata opening and contact GS present within. According to Zobayed et al. (2001) the stomata of Brassica oleracaea are about 1-5 $\mu \mathrm{m}$ 


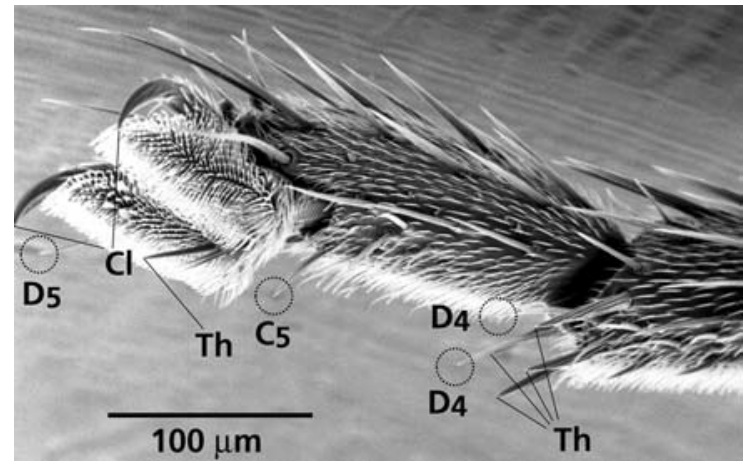

Fig. 8 Scanning electron microscopic view from lateral of the distal tip segments $(5,4)$ of the prothorax tarsus of a female Delia radicum: $\mathrm{D}_{5}, \mathrm{D}_{4}, \mathrm{C}_{5}$ are innervated sensilla; Th: hard cuticular thorns; $\mathrm{Cl}$ : claws

wide and 10-12 $\mu \mathrm{m}$ long (depending on the environmental conditions), which matches our measurements on B. napus (unpublished results). The tip of the tarsal sensilla of Delia radicum measure about 1.25$2 \mu \mathrm{m}$ (Isidoro et al. 1994) and thus penetration into the sensilla cannot be excluded. But, this suggestion remains hypothetical as long as we have no data about sensilla tips really entering the stomata opening during walking or drumming by the insects. Moreover, it remains unclear if GS are present in tissues close to the stomata. It is remarkable that already Dethier (1975) noted that the dimensions of insect sensilla and stomata are very similar and suggested that vapours (ITC in the case of Brassicaceae) emanating through the stomata might stimulate olfactory receptor neurones of caterpillars prior to the first bite.

We imagine that the three hypotheses presented are not mutually exclusive and that a combination of mechanisms might be involved. Obviously, the puzzling question how insect herbivores can perceive GS and GS derivatives overlaid by epicuticular waxes of Brassicaceae and Tropaeolaceae has not been solved yet. It is a fascinating microstructural problem for future investigations that the insects' receptors have evidently been designed to overcome.

Acknowledgements This project was funded by the Swiss National Science Foundation, grant 31-65016.01 to ES and by the Sonderforschungsbereich 554 of the Deutsche Forschungsgemeinschaft to KR. We thank Andrea Hauser, Thomas Poiger, and Bruno Patrian, Agroscope ChanginsWädenswil at Wädenswil, Switzerland for analysing the TTF of our surface extracts. We appreciate that Caroline Müller and two unknown reviewers discussed and improved the content and Jean Berüter-Cassels clarified and corrected the manuscript.

\section{References}

Agerbirk N, De Vos M, Kim JH, Jander G (2008) Indole glucosinolate breakdown and its biological effects. Phytochem Rev (in review)

Alborn H, Karlsson H, Lundgren L, Ruuth P, Stenhagen G (1985) Resistance in crop species of the genus Brassica to oviposition by the turnip root fly, Hylemya floralis. Oikos 44(1):61-69. doi:10.2307/3544044

Andréasson E, Jørgensen LB (2003) Localization of plant myrosinases and glucosinolates. In: Romeo JT (ed) Recent advances in phytochemistry, vol 37. Pergamon, Amsterdam, pp 79-99

Barker AM, Molotsane R, Müller C, Schaffner U, Städler E (2006) Chemosensory and behavioural responses of the turnip sawfly, Athalia rosae, to glucosinolates and isothiocyanates. Chemoecology 16(4):209-218. doi:10.1007/ s00049-006-0349-5

Bart KM, Williams EH (1993) Use of dental wax for the study of insect behavior by scanning electron-microscopy. Microsc Res Tech 26(2):180-181. doi:10.1002/jemt. 1070260213

Baur R, Birch ANE, Hopkins RJ, Griffiths DW, Simmonds MSJ, Städler E (1996) Oviposition and chemosensory stimulation of the root flies Delia radicum and D. floralis in response to plants and leaf surface extracts from resistant and susceptible Brassica genotypes. Entomol Exp Appl 78(1):61-75. doi:10.1007/BF00304457

Baur R, Haribal M, Renwick JAA, Städler E (1998) Contact chemoreception related to host selection and oviposition behaviour in the monarch butterfly, Danaus plexippus. Physiol Entomol 23(1):7-19. doi:10.1046/j.1365-3032. 1998.2310007.x

Bernays EA, Blaney WM, Chapman RF, Cook AG (1975) The problems of perception of leaf-surface chemicals by locust contact chemoreceptors. In: Denton AD, Coghlan JP (eds) Olfaction and Taste V. Academic, New York, pp 227-229

Blaney WM, Simmonds MSJ (1994) Effect of age on the responsiveness of peripheral chemosensory sensilla of the turnip root fly (Delia floralis). Entomol Exp Appl 70(3):253-262. doi:10.1007/BF02380559

Blight MM, Pickett JA, Wadhams LJ, Woodcock CM (1995) Antennal perception of oilseed rape, Brassica napus (Brassicaceae), volatiles by the cabbage seed weevil Ceutorhynchus assimilis (Coleoptera: Curculionidae). J Chem Ecol 21(11):1649-1664. doi:10.1007/BF02033667

De Candolle D (1804) Essai sur les propriétés médicales des plantes, comparées avec leurs formes extérieures et leur classification naturelle. L'imprimerie de Didot Jeune de l'imprimeur de l'école de médicine, rue des MaconsSorbonne, Paris

De Jong R, Städler E (1999) The influence of odour on the oviposition behaviour of the cabbage root fly. Chemoecology 9(4):151-154. doi:10.1007/s000490050047

De Jong R, Städler E (2001) Sensilla on cabbage root fly tarsae sensitive to egg-associated compounds. Chemoecology 11(3):145-147. doi:10.1007/PL00001844 
De Jong R, Maher N, Patrian B, Städler E, Winkler T (2000) Rutabaga roots, a rich source of oviposition stimulants for the cabbage root fly. Chemoecology 10(4):205-209. doi: 10.1007/PL00001824

Dethier VG (1954) Evolution of feeding preferences in phytophagous insects. Evolution Int J Org Evolution 8:33-54. doi: $10.2307 / 2405664$

Dethier VG (1975) The monarch revisited. J Kans Entomol Soc 48(2): 129-140

De Vos M, Kriksunov K, Jander G (2008) Indole-3-acetonitrile production from indole glucosinolates deters oviposition by Pieris rapae (white cabbage butterfly). Plant Physiol 146(3):916-926. doi:10.1104/pp.107.112185

Du YJ, van Loon JJA, Renwick JAA (1995) Contact chemoreception of oviposition-stimulating glucosinolates and an oviposition-deterrent cardenolide in 2 subspecies of Pieris napi. Physiol Entomol 20(2):164-174. doi:10.1111/ j.1365-3032.1995.tb00813.x

Eigenbrode SD, Espelie KE (1995) Effects of plant epicuticular lipids on insect herbivores. Annu Rev Entomol 40: 171-194. doi:10.1146/annurev.en.40.010195.001131

Eigenbrode SD, Jetter R (2002) Attachment to plant surface waxes by an insect predator. Integr Comp Biol 42(6):1091-1099. doi:10.1093/icb/42.6.1091

Evans KA, Allen-Williams LJ (1992) Electroantennogram responses of the cabbage seed weevil, Ceutorhynchus assimilis, to oilseed rape, Brassica napus ssp oleifera, volatiles. J Chem Ecol 18(9):1641-1659. doi:10.1007/ BF00993236

Finch S (1978) Volatile plant-chemicals and their effect on host plant finding by the cabbage root fly (Delia brassicae). Entomol Exp Appl 24(3):350-359. doi:10.1007/ BF02385085

Finch S, Skinner G (1982) Trapping cabbage root flies in traps baited with plant extracts and with natural and synthetic isothiocyanates. Entomol Exp Appl 31(2):133-139

Fujikawa K, Seno K, Ozaki M (2006) A novel Takeout-like protein expressed in the taste and olfactory organs of the blowfly, Phormia regina. FEBS J 273(18):4311-4321. doi:10.1111/j.1742-4658.2006.05422.x

Gouinguené SPD, Städler E (2005) Comparison of the sensitivity of four Delia species to host and non-host plant compounds. Physiol Entomol 30(1):62-74. doi: 10.1111/j.0307-6962.2005.00432.x

Gouinguené SPD, Städler E (2006) Comparison of the egglaying behaviour and electrophysiological responses of Delia radicum and Delia floralis to cabbage leaf compounds. Physiol Entomol 31(4):382-389. doi:10.1111/ j.1365-3032.2006.00532.x

Griffiths DW, Deighton N, Birch ANE, Patrian B, Baur R, Städler E (2001) Identification of glucosinolates on the leaf surface of plants from the Cruciferae and other closely related species. Phytochem 57(5):693-700. doi: 10.1016/S0031-9422(01)00138-8

Holloway PJ, Brown GA, Baker EA, Macey MJK (1977) Chemical composition and ultrastructure of the epicuticular wax in three lines of Brassica napus (L). Chem Phys Lipids 19(2):114-127. doi:10.1016/0009-3084(77)90092-5

Hopkins RJ, Birch ANE, Griffiths DW, Baur R, Städler E, McKinlay RG (1997) Leaf surface compounds and oviposition preference of turnip root fly Delia floralis: the role of glucosinolate and non-glucosinolate compounds. J Chem Ecol 23(3):629-643. doi:10.1023/B:JOEC.0000 $006400.59702 .2 \mathrm{f}$

Hurter J, Ramp T, Patrian B, Städler E, Roessingh P, Baur R et al (1999) Oviposition stimulants for the cabbage root fly: isolation from cabbage leaves. Phytochem 51(3):377382. doi:10.1016/S0031-9422(99)00062-X

Inoue TA (2006) Morphology of fore-tarsal ventral surfaces of Japanese Papilio butterflies and relations between these morphology, phylogeny and host-plant preferring hierarchy. Zoolog Sci 23(2):169-189. doi:10.2108/zsj.23.169

Isidoro N, Solinas M, Baur R, Roessingh P, Städler E (1994) Functional morphology of a tarsal sensillum of Delia radicum L. (Diptera: Anthomyiidae) sensitive to important host-plant compounds. Int J Insect Morphol Embryol 23(2):115-125. doi:10.1016/0020-7322(94)90005-1

Isidoro N, Bartlet E, Ziesmann J, Williams IH (1998) Antennal contact chemosensilla in Psylliodes chrysocephala responding to cruciferous allelochemicals. Physiol Entomol 23(2):131-138. doi:10.1046/j.1365-3032.1998.232 066.x

Jeffree CE (1986) The cuticle, epicuticular waxes and trichomes of plants, with reference to their structure, functions and evolution. In: Juniper B, Southwood R (eds) Insects and the plant surface. Edward Arnold, London, pp 23-64

Jeffree CE (1996) Structure and ontogeny of plant cuticles. In: Kerstiens G (ed) Plant cuticles. BIOS Scientific Publishers Ltd, Oxford, pp 33-82

Juniper BE, Jeffree CE (1983) Plant surfaces. Edward Arnold, London

Jørgensen K, Kvello P, Almaas TJ, Mustaparta H (2006) Two closely located areas in the suboesophageal ganglion and the tritocerebrum receive projections of gustatory receptor neurons located on the antennae and the proboscis in the moth Heliothis virescens. J Comp Neurol 496(1):121134. doi: $10.1002 / \mathrm{cne} .20908$

Knoll D, Schreiber L (2000) Plant-microbe interactions: wetting of ivy (Hedera helix L.) leaf surfaces in relation to colonization by epiphytic microorganisms. Microb Ecol 40(1):33-42

Koch K, Hartmann KD, Schreiber L, Barthlott W, Neinhuis C (2006) Influences of air humidity during the cultivation of plants on wax chemical composition, morphology and leaf surface wettability. Environ Exp Bot 56(1):1-9. doi: 10.1016/j.envexpbot.2004.09.013

Long LM, Patel HP, Cory WC, Stapleton AE (2003) The maize epicuticular wax layer provides UV protection. Funct Plant Biol 30(1):75-81. doi:10.1071/FP02159

Ma W-C (1972) Dynamics of feeding responses in Pieris brassicae Linn. as a function of chemosensory input: a behavioural, ultrastructural and electrophysiological study. Meded Landbouwhogeschool Wageningen 7211:1-162

Ma W-C, Schoonhoven LM (1973) Tarsal contact chemosensory hairs of the large white butterfly, Pieris brassicae and their possible rôle in oviposition behaviour. Entomol Exp Appl 16:343-357. doi:10.1007/BF00334245

Messchendorp L, Smid HM, van Loon JJA (1998) The role of an epipharyngeal sensillum in the perception of feeding deterrents by Leptinotarsa decemlineata larvae. J Comp 
Physiol A Neuroethol Sens Neural Behav Physiol 183(2):255-264

Miles CI, del Campo ML, Renwick JAA (2005) Behavioral and chemosensory responses to a host recognition cue by larvae of Pieris rapae. J Comp Physiol A Neuroethol Sens Neural Behav Physiol 191(2):147-155

Mitchell BK, Justus KA, Asaoka K (1996) Deterrency and the variable caterpillar: Trichoplusia $n i$ and sinigrin. Entomol Exp Appl 80(1):27-31. doi:10.1007/BF00194717

Müller C (2006) Plant insect interactions on cuticular surfaces. In: Riederer M, Müller C (eds) Biology of the plant cuticle. Annual Plant Reviews, vol 23. Blackwell Publishing, Oxford, pp 398-422

Müller C (2008) Resistance at the plant cuticle. In: Schaller A (ed) Induced plant resistance to herbivory. Springer, pp 107-129

Müller C, Riederer M (2005) Plant surface properties in chemical ecology. J Chem Ecol 31(11):2621-2651. doi: 10.1007/s10886-005-7617-7

Müller C, Agerbirk N, Olsen CE, Boevé JL, Schaffner U, Brakefield PM (2001) Sequestration of host plant glucosinolates in the defensive hemolymph of the sawfly Athalia rosae. J Chem Ecol 27(12):2505-2516. doi:10.1023/A: 1013631616141

Nielsen JK (1978) Host plant discrimination within cruciferae-feeding responses of 4 leaf beetles (ColeopteraChrysomelidae) to glucosinolates, cucurbitacins and cardenolides. Entomol Exp Appl 24(3):41-54. doi:10.1007/ BF00334172

Nielsen JK, Hansen ML, Agerbirk N, Petersen BL, Halkier BA (2001) Responses of the flea beetles Phyllotreta nemorum and $P$. cruciferae to metabolically engineered Arabidopsis thaliana with an altered glucosinolate profile. Chemoecology 11(2):75-83. doi:10.1007/PL00001835

Nottingham SF, Hardie J, Dawson GW, Hick AJ, Pickett JA, Wadhams LJ et al (1991) Behavioral and electrophysiological responses of aphids to host and nonhost plant volatiles. J Chem Ecol 17(6):1231-1242. doi:10.1007/BF 01402946

Perleb KJ (1818) Versuch über die Arzneikräfte der Pflanzen verglichen mit den äusseren Formen und der natürlichen Klasseneinteilung derselben (Translation of De Candolle 1804). Sauerländer, Aarau

Popp C, Burghardt M, Friedmann A, Riederer M (2005) Characterization of hydrophilic and lipophilic pathways of Hedera helix L. cuticular membranes: permeation of water and uncharged organic compounds. J Exp Bot 56(421):2797-2806. doi:10.1093/jxb/eri272

Reifenrath K, Müller C (2008) Multiple feeding stimulants in Sinapis alba for the oligophagous leaf beetle Phaedon cochleariae. Chemoecology 18(1):19-27. doi:10.1007/ s00049-007-0389-5

Reifenrath K, Riederer M, Müller C (2005) Leaf surface wax layers of Brassicaceae lack feeding stimulants for Phaedon cochleariae. Entomol Exp Appl 115(1):41-50. doi: 10.1111/j.1570-7458.2005.00242.x

Renwick JAA, Radke CD, Sachdev-Gupta K, Städler E (1992) Leaf surface chemicals stimulating oviposition by Pieris rapae on cabbage. Chemoecology 3(1):33-38. doi: 10.1007/BF01261454
Renwick JAA, Haribal M, Gouinguené S, Städler E (2006) Isothiocyanates stimulating oviposition by the diamondback moth, Plutella xylostella. J Chem Ecol 32(4): 755-766. doi:10.1007/s10886-006-9036-9

Roessingh P, Städler E (1990) Foliar form, color and surface characteristics influence oviposition behavior in the cabbage root fly Delia radicum. Entomol Exp Appl 57(1): 93-100. doi:10.1007/BF00349599

Roessingh P, Städler E, Schöni R, Feeny P (1991) Tarsal contact chemoreceptors of the black swallowtail butterfly, Papilio polyxenes: responses to phytochemicals from host- and non-host plants. Physiol Entomol 16(4): 485-495. doi:10.1111/j.1365-3032.1991.tb00588.x

Roessingh P, Städler E, Fenwick GR, Lewis JA, Nielsen JK, Hurter J et al (1992) Oviposition and tarsal chemoreceptors of the cabbage root fly are stimulated by glucosinolates and host-plant extracts. Entomol Exp Appl 65(3):267-282. doi:10.1007/BF02343860

Roessingh P, Städler E, Baur R, Hurter J, Ramp T (1997) Tarsal chemoreceptors and oviposition behaviour of the cabbage root fly (Delia radicum) sensitive to fractions and new compounds of host-leaf surface extracts. Physiol Entomol 22(2):140-148. doi:10.1111/j.1365-3032.1997. tb01151.x

Rohloff J, Bones AM (2005) Volatile profiling of Arabidopsis thaliana-putative olfactory compounds in plant communication. Phytochem 66(16):1941-1955. doi:10.1016/j. phytochem.2005.06.021

Rojas JC (1999) Electrophysiological and behavioral responses of the cabbage moth to plant volatiles. J Chem Ecol 25(8):1867-1883. doi:10.1023/A:1020985917202

Root RB, Kareiva PM (1984) The search for resources by cabbage butterflies (Pieris rapae): ecological consequences and adaptive significance of markovian movements in a patchy environment. Ecology 65:147165. doi: $10.2307 / 1939467$

Schoonhoven LM (1967) Chemoreception of mustard oil glucosides in larvae of Pieris brassicae L. Proc K Ned Akad Wet C 5:556-568

Schoonhoven LM, van Loon JJA, Dicke M (2005) Insect-plant biology, 2nd edn. Oxford University Press, Oxford

Shields VDC, Mitchell BK (1995a) Sinigrin as a feeding deterrent in 2 crucifer-feeding, polyphagous lepidopterous species and the effects of feeding stimulant mixtures on deterrency. Philos Trans R Soc Lond B Biol Sci 347(1322):439-446. doi:10.1098/rstb.1995.0035

Shields VDC, Mitchell BK (1995b) Responses of maxillary styloconic receptors to stimulation by sinigrin, sucrose and inositol in 2 crucifer-feeding, polyphagous lepidopterous species. Philos Trans R Soc Lond B Biol Sci 347(1322):447-457. doi:10.1098/rstb.1995.0036

Shroff R, Vergara F, Muck A, Svatoš A, Gershenzon J (2008) Mass spectrometric imaging of glucosinolates in Arabidopsis thaliana leaves reveals a non-uniform distribution that has significance for plant defense. Proc Natl Acad Sci USA 105(16):6196-6201. doi:10.1073/pnas.0711730105

Simmonds MSJ, Blaney WM, Mithen R, Birch ANE, Lewis J (1994) Behavioral and chemosensory responses of the turnip root fly (Delia floralis) to glucosinolates. Entomol Exp Appl 71(1):41-57. doi:10.1007/BF02380568 
Spencer JL (1996) Waxes enhance Plutella xylostella oviposition in response to sinigrin and cabbage homogenates. Entomol Exp Appl 81(2):165-173. doi:10.1007/BF00 192141

Spencer JL, Pillai S, Bernays EA (1999) Synergism in the oviposition behavior of Plutella xylostella: sinigrin and wax compounds. J Insect Behav 12(4):483-500. doi: 10.1023/A:1020914723562

Städler E (2002) Plant chemical cues important for egg deposition by herbivorous insects. In: Hilker M, Meiners $\mathrm{T}$ (eds) Chemoecology of insect eggs and egg deposition. Blackwell, Berlin, pp 171-204

Städler E, Roessingh P (1991) Perception of surface chemicals by feeding and ovipositing insects. In: Szentesi A, Jermy T (eds) Insect-plants '89. Symposia Biologica Hungarica, vol 39. Akadémiai Kiadó, Budapest Hungary, pp 71-86

Städler E, Schöni R (1990) Oviposition behavior of the cabbage root fly, Delia radicum (L.), influenced by host plant-extracts. J Insect Behav 3(2):195-209. doi:10.1007/ BF01417912

Städler E, Renwick JAA, Radke CD, Sachdev-Gupta K (1995) Tarsal contact chemoreceptor response to glucosinolates and cardenolides mediating oviposition in Pieris rapae. Physiol Entomol 20(2):175-187. doi:10.1111/j.13653032.1995.tb00814.x

Städler E, Baur R, de Jong R (2002) Sensory basis of host-plant selection: in search of the "fingerprints" related to oviposition of the cabbage root fly. Acta Zool Acad Sci Hung 48(1):265-280

Strauss SY, Irwin RE, Lambrix VM (2004) Optimal defence theory and flower petal colour predict variation in the secondary chemistry of wild radish. J Ecol 92(1):132-141. doi:10.1111/j.1365-2745.2004.00843.x

Sutcliffe JF, Mitchell BK (1982) Characterization of galeal sugar and glucosinolate-sensitive cells in Entomoscelis americana adults. J Comp Physiol 146(3):393-399. doi: 10.1007/BF00612708

Tanton MT (1977) Response to food plant stimuli by larvae of mustard beetle Phaedon cochleariae. Entomol Exp Appl 22(2):113-122. doi:10.1007/BF00302567

Terofal F (1965) Zum Problem der Wirtsspezifität bei Pieriden (Lep.). Unter besonderer Berücksichtigung der einheimischen Arten Pieris brassicae L., P. napi L. und $P$. rapae L. Mitt Munch Entomol Ges 55:1-76
Thangstad OP, Bones AM, Holton S, Moen L, Rossiter JT (2001) Microautoradiographic localisation of a glucosinolate precursor to specific cells in Brassica napus L. embryos indicates a separate transport pathway into myrosin cells. Planta 213(2):207-213. doi:10.1007/s004250000491

Thangstad OP, Gilde B, Chadchawan S, Seem M, Husebye H, Bradley D et al (2004) Cell specific, cross-species expression of myrosinases in Brassica napus, Arabidopsis thaliana and Nicotiana tabacum. Plant Mol Biol 54(4):597611. doi:10.1023/B:PLAN.0000038272.99590.10

Thorsteinson AJ (1953) The chemotactic responses that determine host specificity in an oligophagous insect (Plutella maculipennis Curt.) Lepidoptera). Can J Zool 31:52-72

Tollsten L, Bergström G (1988) Headspace volatiles of whole plants and macerated plant-parts of Brassica and Sinapis. Phytochem 27(7):4013-4018. doi:10.1016/0031-9422(88) 83085-1

Van Loon JJA, Blaakmeer A, Griepink FC, van Beek TA, Schoonhoven LM, de Groot A (1992) Leaf surface compound from Brassica oleracea (Cruciferae) induces oviposition by Pieris brassicae (Lepidoptera: Pieridae). Chemoecology 3(1):39-44. doi:10.1007/BF01261455

Van Loon JJA, Wang CZ, Nielsen JK, Gols R, Qiu YT (2002) Flavonoids from cabbage are feeding stimulants for diamondback moth larvae additional to glucosinolates: chemoreception and behaviour. Entomol Exp Appl 104(1):27-34. doi:10.1023/A:1021250621756

Verschaffelt E (1910) The cause determining the selection of food in some herbivorous insects. Proc K Ned Akad Wet C 13:536-542

Wallbank BE, Wheatley GA (1976) Volatile constituents from cauliflower and other crucifers. Phytochem 15(5):763766. doi:10.1016/S0031-9422(00)94438-8

Wieczorek H (1976) Glycoside receptor of larvae of Mamestra brassicae L (Lepidoptera, Noctuidae). J Comp Physiol 106(2):153-176. doi:10.1007/BF00620496

Zobayed SMA, Armstrong J, Armstrong W (2001) Leaf anatomy of in vitro tobacco and cauliflower plantlets as affected by different types of ventilation. Plant Sci 161(3):537-548. doi:10.1016/S0168-9452(01)00438-1

Zohren E (1968) Laboruntersuchungen zu Massenzucht, Lebensweise, Eiablage und Eiablageverhalten der Kohlfliege, Chortophila brassicae Bouché (Diptera, Anthomyiidae). Z Angew Entomol 62(2):139-188 